\title{
Assessing the impact of monocular deprivation on visual evoked potentials, behavior, and visual plasticity in juvenile mice
}

\author{
Suzhen Ding ${ }^{1 \wedge}$, Chunxian Yang ${ }^{2} \wedge$, Hefei $\mathrm{Zhu}^{1} \wedge$, Shaomin $\mathrm{Li}^{3}$, Lan $\mathrm{Li}^{1 \wedge}$ \\ ${ }^{1}$ Department of Ophthalmology, the First People's Hospital of Kunming, Kunming, China; ${ }^{2}$ Key Laboratory of Animal Models and Human Disease \\ Mechanisms, Lab of Learning and Memory, Kunming Institute of Zoology, Chinese Academy of Sciences, Kunming, China; ${ }^{3}$ Ann Romney Center \\ for Neurologic Diseases, Brigham and Women's Hospital and Harvard Medical School, Boston, MA, USA \\ Contributions: (I) Conception and design: L Li, S Li; (II) Administrative support: L Li; (III) Provision of study materials or patients: S Ding; (IV) \\ Collection and assembly of data: S Ding, C Yang; (V) Data analysis and interpretation: S Ding, C Yang, H Zhu; (VI) Manuscript writing: All authors; \\ (VII) Final approval of manuscript: All authors. \\ Correspondence to: Lan Li. Department of Ophthalmology, the First People's Hospital of Kunming, Kunming, China. Email: 641106144@qq.com.
}

\begin{abstract}
Background: The physiological mechanisms which underlie amblyopia are predicted using animal models which assess the impact of amblyogenic factors on visual function. This study used monocular-deprived mice as an amblyopic model to assess visual function by flash visual evoked potentials (fVEP), behavioral assessment, and visual plasticity.

Methods: A total of 294 C57BL/6J mice (both genders) were used in this study. The mice were divided into the normal control (NC) group and monocular deprivation (MD) group. After mice were anesthetized with pentobarbital, fVEP was recorded. Long-term potentiation (LTP) was recorded from primary visual cortex slices. Behavioral assessment of visual function was performed using a visual water trapezoidal-shaped pool with a release chute, a hidden platform, and a middle divider.

Results: All fVEP results showed that N1 waves and P2 waves were repeatable and N1-P2 amplitude was the most stable indicator. The amplitude of N1-P2 of MD eyes was significantly lower than that of nondeprived eyes or NC eyes. LTP failed to be induced in the visual cortex V1 area corresponding to deprived eyes in the MD group but could be induced successfully in the visual cortex V1 area corresponding to nondeprived eyes in the MD group. Behavioral vision testing also showed a longer time to reach the platform in MD mice compared to NC mice. The correlation coefficient suggested that LTP is the better indicator for visual impairment.
\end{abstract}

Conclusions: The fVEP can be utilized as an index of amblyopic changes in mice, which correlates well with behavioral results.

Keywords: Visual evoked potential (VEP); long-term potentiation (LTP); visual water maze; monocular deprivation (MD); mice

Submitted Nov 22, 2021. Accepted for publication Jan 12, 2022.

doi: 10.21037/atm-21-6723

View this article at: https://dx.doi.org/10.21037/atm-21-6723

\section{Introduction}

Visual function is an essential ability to perceive external information in both animals and humans. In various biomedical research fields, mice have become the most widely studied mammalian model of human diseases. Considerable understanding of the biochemical pathways and pharmacology of the mouse visual system has been acquired $(1,2)$. The availability of genetic, optical, and

^ ORCID: Suzhen Ding, 0000-0003-4957-3371; Chunxian Yang, 0000-0002-4735-3896; Hefei Zhu, 0000-0001-7765-0421; Lan Li, 00000002-9249-441X. 
physiological technologies makes the mouse a valuable model for studying mammalian brain circuits. Also, because mouse strains can readily hybridize and reproduce, and the genome is completely sequenced, mice provide an unparalleled opportunity to study specific types of cells and brain circuits (3). Researchers usually use mice to study visual function through anatomical assessment of visual function (such as refraction of the eye, fundus examination, and rapid histological examination) (4), electrophysiological tests [include electroretinogram (ERG) and visual evoked potential (VEP)] (5-7), or behavioral assessments [such as optomotor response (OMR), forced-choice swimming task, go/no-go licking task, visual cliff, and elevated plus maze] $(4,8)$. In recent years, many behavioral assessment methods have been used to elucidate the visual function of rodents (8-12). The most promising behavioral measurement for mouse vision is the forced-choice swimming task, or visual water test $(13,14)$, which along with the Morris water maze is the most widely used laboratory behavioral test to assess learning and memory in rodents (15). However, visual function is complex, and there is no generally agreed standard to assess mouse vision.

Amblyopia is considered to be one of the leading causes of visual impairment in children and adults. During a certain period after birth, the visual system is plastic and can change neural connections and synaptic structures according to environmental stimuli, called the critical period of visual development. Therefore, intervention with experimental animals during the critical period of visual development can simulate the pathogenesis of human amblyopia. The animals commonly used in building amblyopia models are rats, mice, cats, monkeys, etc. Because mice are relatively cheap, easy to raise, and have a short modeling cycle, they have been widely used in building amblyopia models. The main methods of constructing amblyopia animal models include eyelid sutures [such as monocular deprivation (MD)], rectus amputation, dark environment feeding, etc. Most of the information regarding human normal and amblyopic visual function is based on psychophysics and electrophysiology studies. Since the pioneering studies conducted by Hubel and Wiesel in 1963, MD-induced amblyopia has been widely used to study the plasticity of the visual cortex in animal experiments (16-18). MD can induce myopia and amblyopia, but myopia and amblyopia are two kinds of eye diseases. Amblyopia is an ophthalmic disease caused by abnormal visual experience (shape deprivation, strabismus, anisometropia, high ametropia) in one eye or two eyes with reduced best-corrected visual acuity, but no organic changes in the eye examination. Myopia is when the eye is in a relaxed state, parallel light enters the eye and focuses on the front of the retina, which results in the inability to form a clear image on the retina. Myopia is a kind of ametropia. If high myopia occurs during visual development and if it is not corrected in time, it may cause amblyopia.

To investigate the molecular mechanisms of amblyopia in animals, assessing visual function in animal models is the most important procedure. Although there have been some reports of visual function assessment by VEP, behavioral tests, or visual plasticity in mice (4), none of them combined all methods to compare visual function in normal and MD mice. Here, we used an MD mouse model as an amblyopic model to assess visual function by flash visual evoked potentials (fVEP), behavioral assessment, and visual plasticity in wild-type mice. We demonstrated that the physiological changes of fVEP and synaptic plasticity were in line with the psychophysical measurement. A physiological and straightforward method for assessing mice vision is fVEP. Changes in N1-P2 amplitude from repeated tests can be a reliable evaluation indicator. Behavioral tests by force swimming tasks also reflect the activity of the primary visual cortex.

We present the following article in accordance with the ARRIVE reporting checklist (available at https://atm. amegroups.com/article/view/10.21037/atm-21-6723/rc).

\section{Methods}

\section{Animals}

All experiments were performed on 3-week-old C57BL/6J mice (both genders) obtained from Kunming Institute of Zoology (Chinese Academy of Sciences). Animals were housed in standard cages and conditions (temperature $22^{\circ} \mathrm{C}$, 12-hour light/dark cycle), and were provided with food and water ad libitum. Due to the different methods of recording and stimulation in different laboratories, the latencies and amplitudes of fVEP responses under different conditions (electrodes type, stimulation intensities, rates, anesthetic agents) may yield different parameters. In order to achieve the stability and repeatability of fVEP detection of mice in our laboratory, 294 normal C57BL/6J mice were detected for fVEP, and all mice were recovered after detection (no harm to the mice). From these 294 normal mice, only 20 were randomly selected as the normal control (NC) group, including brain section records (5 mice) and behavioral tests $(15$ mice). The other 34 were randomly 
selected for monocular sutures as MD group, including brain section records ( 5 mice) and behavioral tests (17 mice) for further experiments. For MD group comparisons, same aged littermates were chosen as a control group. In addition, to verify the reliability of fVEP, we recorded fVEP in 8 littermates continuously for 7 days. Simple randomization was used, and only those who determined the groups knew the grouping results.

\section{Ethical statement}

The First People's Hospital of Kunming is an affiliated hospital of Kunming Medical University. All animal experiments were approved by the Kunming Medical University Animal Care Committee (No. kmmu2018010), and all procedures were conducted in accordance with the Association for Research in Vision and Ophthalmology (ARVO) Statement for Use of Animals in Ophthalmic Vision and Research. A protocol was prepared before the study without registration. All efforts were made to minimize animal suffering and the number of animals used in experiments.

\section{MD procedure}

Mice were anesthetized with pentobarbital sodium $(80 \mathrm{mg} / \mathrm{kg}$, i.p.). The upper and lower eyelid margins were sterilized with disinfectant solution, then eyelid margins were cut off. The surgical eye was closed with a continuous suture and was coated with erythromycin oculentum. After surgery was completed, animals were placed in a constant temperature blanket for recovery from the anesthetic. After waking up from the anesthetic, if mice moved around the cage normally, they were returned to the animal facility. Distress, pain, and discomfort were monitored every 8 hours for 3 days. If the suture was not intact or the wound was infected, animals were discarded.

\section{fVEP recording}

According to the methods of Strain and Tedford (19), fVEP was recorded from 294 non-deprived and MD mice aged $\mathrm{P} 21-\mathrm{P} 40$. The mice were used for further experiments after they fully recovered. VEP responses were assessed with the RETI-port/scan21 (Roland Consult, Wiesbaden, Germany). Mice were anesthetized with pentobarbital sodium $(80 \mathrm{mg} / \mathrm{kg}$, i.p.) and fixed on the experimental platform (Figure 1A). The appropriate level of anesthesia was verified by checking the presence of a tail-pinching reflex. During the experiment, body temperature was maintained at $36.5 \pm 0.5^{\circ} \mathrm{C}$ by a constant temperature blanket system with a rectal thermometer probe. The recording electrodes were inserted under the scalp of the center of the connection between the 2 ears. A reference electrode was placed on the cheek pouches, and a grounding electrode was placed on the tail of the mouse. For each VEP recording session, 3 trains of 100 flash stimuli $\left(5 \mathrm{~dB}\right.$, i.e., $9.49 \mathrm{CDs} / \mathrm{m}^{2}$ intensity, $10 \mu$ s duration, $1 \mathrm{~Hz}$ frequency) were delivered by using a flashlight stimulator placed $20 \mathrm{~cm}$ away from the stimulated eyes. The stimulus was presented at $1 \mathrm{~Hz}$, with a sampling frequency of $1 \mathrm{kHz}$ and a bandpass filter of 1-50 Hz. At the end of each recording, the mice were placed in their cages where they could move and fully orient for the next $10-15$ minutes.

\section{Primary visual cortex slice preparation}

Field potentials were recorded in the V1 area of the mouse visual cortex as previously described (20). Mice between P25-P35 were deeply anesthetized with pentobarbital sodium $(80 \mathrm{mg} / \mathrm{kg}$, i.p.). After confirming the absence of a pinch or righting reflex, mice were decapitated, and the brain was rapidly removed and placed in ice-cold oxygenated sucrose-replaced artificial cerebrospinal fluid (ACSF) cutting buffer containing the following (in $\mathrm{mM}$ ): 208 sucrose, $2.0 \mathrm{KCl}, 1.25 \mathrm{NaH}_{2} \mathrm{PO}_{4} \cdot \mathrm{H}_{2} \mathrm{O}, 3 \mathrm{MgCl}_{2}$, $1 \mathrm{CaCl}_{2}, 10 \mathrm{D}$-glucose, $26 \mathrm{NaHCO}_{3}, \mathrm{pH} \mathrm{7.4,}$ $\sim 315 \mathrm{mOsmol}$. The $350 \mu \mathrm{m}$ coronal sections were cut and transferred to the ACSF holding chamber containing the following (in $\mathrm{mM}$ ): $124 \mathrm{NaCl}, 2 \mathrm{KCl}, 2 \mathrm{MgSO}_{4}$, $1.25 \mathrm{NaH}_{2} \mathrm{PO}_{4}, 2 \mathrm{CaCl}_{2}, 26 \mathrm{NaHCO}_{3}, 10$ D-glucose, $\mathrm{pH} 7.4, \sim 310 \mathrm{mOsmol}$. Sections were incubated for 40 minutes, then restored at room temperature $\left(22^{\circ} \mathrm{C}\right)$ for at least 1 hour before electrophysiological recordings started.

\section{Long-term potentiation (LTP) recording}

Neurons communicate information through synapses. Synapses have plasticity, and long-term synaptic plasticity manifests as LTP and long-term depression (LTD). This study evaluated the plasticity of the visual cortex by detecting the LTP of neurons in the visual cortex. LTP refers to giving neuron A a low-frequency stimulation, which transmits the signal to neuron $\mathrm{B}$. At this time, lower excitatory postsynaptic potential (EPSP) can be recorded. When a series of high-frequency stimulation (HFS) is 

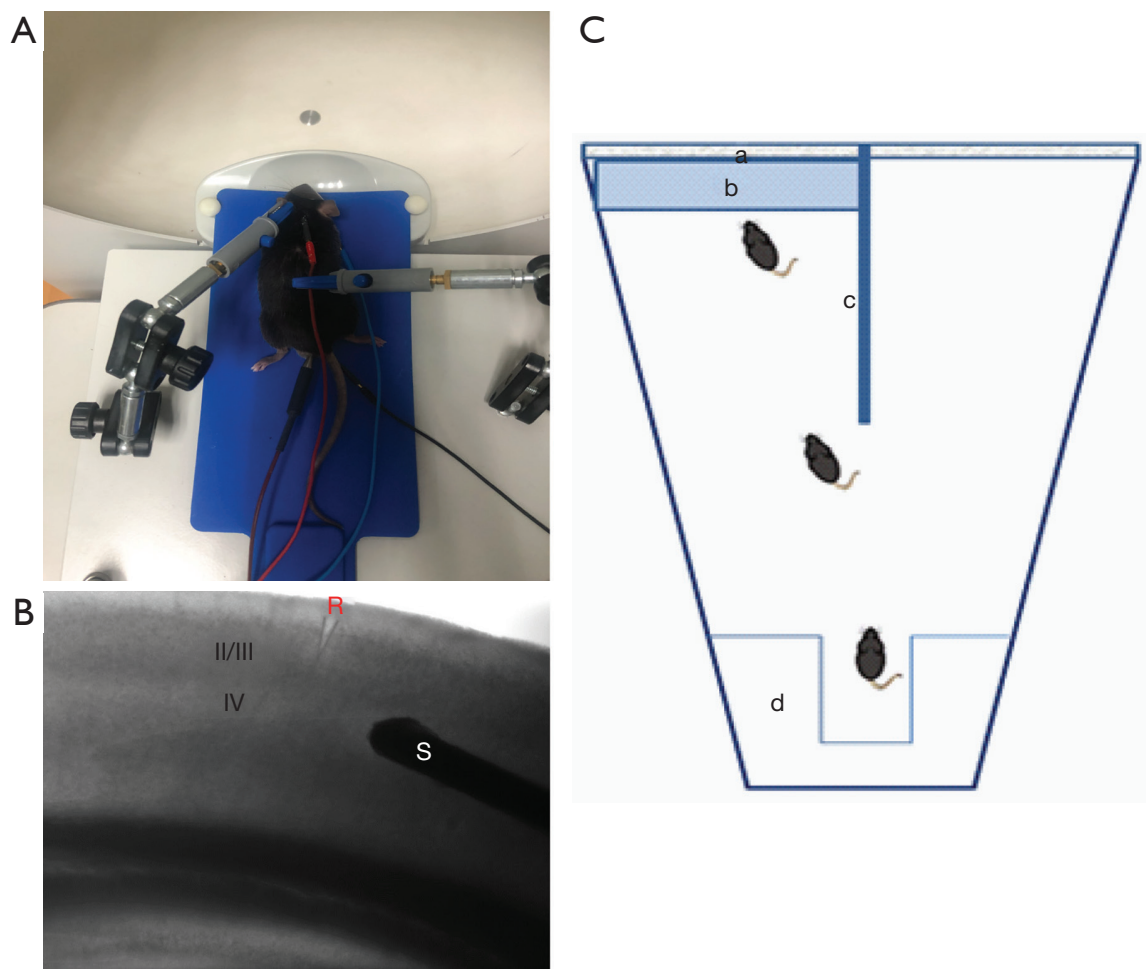

Figure 1 Schematic diagrams of the methods used in this study. (A) Flash VEP recording. (B) LTP recording in visual cortex slices with a stimulation electrode (S) placed in layer IV of the visual cortex (V1) area and a recording electrode (R) placed in layer II/III of the visual cortex to record the fEPSP. (C) Visual behavioral test box. a, visible sign (grating); b: hidden platform; c: divider; d: release chute. VEP, visual evoked potential; LTP, long-term potentiation; fEPSP, field excitatory postsynaptic potential.

given to neuron A, EPSP will increase rapidly, at this time, turning the stimulus into low-frequency stimulation again. If EPSP is still maintained at a high level, it is called the LTP phenomenon. Increased LTP indicates increased synaptic plasticity, and decreased or disappeared LTP indicates decreased or lost synaptic plasticity in the visual cortex.

Brain slices were transferred to a submersion-type recording chamber and perfused with oxygenated ACSF (bubbled $95 \% \mathrm{O}_{2} / 5 \% \mathrm{CO}_{2}$ at room temperature) at a rate of $2 \mathrm{~mL} /$ minute. Stimulation electrodes were placed in layer IV of the visual cortex $\mathrm{V} 1$, and recording electrodes were placed in layer II/III of the visual cortex to record the field excitatory postsynaptic potential (fEPSP) (Figure 1B). Test stimuli was delivered at $0.033 \mathrm{~Hz}$ with $40 \%$ stimulation of maximum field potential. The baseline was stably recorded for at least 20 minutes, then HFS was given. Subsequently, 3 HFS (100 Hz for 1 second) was delivered 20 seconds apart to induce LTP. Field potential responses were amplified 10x using an Axopatch 200B. The data was sampled at $10 \mathrm{kHz}$ and filtered at $2 \mathrm{kHz}$. Traces were analyzed using pClamp 9.2. The amplitude of the field potential was estimated using approximately $10-60 \%$ of the total response.

\section{Mouse behavioral experiments}

The apparatus was a visual water box based on the design of Prusky et al. (13). Water temperature was $22-24{ }^{\circ} \mathrm{C}$. Different graphics were put in front of the water maze. A rescue platform was hidden in the water under certain visible graphics (triangles, squares, and vertical gratings). The water maze was divided into 2 channels, and small white plastic granules covered the water. The visible signs were 3 black equilateral triangles $(15 \mathrm{~cm}$ side lengths) placed on each side of the wall of the escape channel and 3 squares ( $15 \mathrm{~cm}$ each side) on each side of the wall without the escape channel. For visual detection, visible graphics (vertical gratings of $0.12 \mathrm{c} / \mathrm{deg}$ ) were placed on the front wall with the escape platform and the triangles and squares were placed on the channel walls (Figure 1C). To test the 

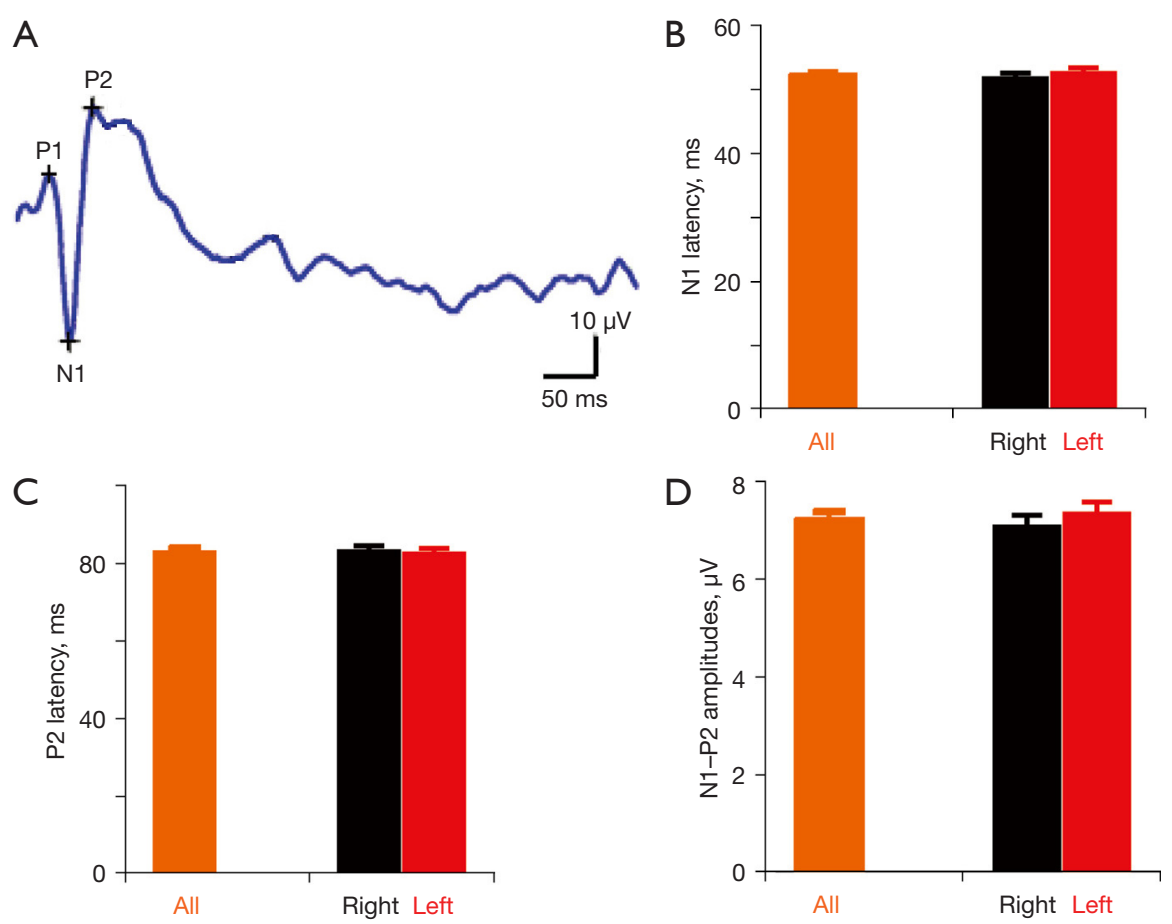

Figure 2 Flash VEP response from NC mice. (A) Representative fVEP response recorded from a normal mouse. (B) Summary of the latency of the N1 wave from a total of 540 eyes (orange) and each eye (right in black, left in red). (C) Summary of the latency of the P2 wave from a total of 540 eyes (orange) and each eye (right in black, left in red). (D) Summary of the peak-to-peak amplitudes of the N1-P2 wave from a total 540 eyes (orange) and each eye (right in black, left in red). VEP, visual evoked potential; NC, normal control; fVEP, flash visual evoked potentials.

effect of MD on visual detection, the sutures were taken off from the deprived eyes and the contralateral non-deprived eye was sutured for the water box study to ensure that MD mice only used the deprived eye to perform the tasks. Mice were put into the release platform to get in the water maze, and they searched hidden escape platforms under the guidance of the graphics. Each mouse was tested 10 times a day. The locations of the escape platform and its related graphics were changed randomly during the tests. The time that each mouse spent on the release platform to the escape platform was recorded. The whole experimental process was recorded by a camera.

\section{Statistical analysis}

All data was analyzed using SPSS 19.0 statistical software and expressed as mean \pm standard error of the mean (SEM) from at least 6 independent recordings. For each mouse, VEP latencies and amplitudes from each eye were averaged. The recorded LTP values were those at 40 minutes after the conditioning stimulus. Behavioral studies yielded the time to reach the platform for each training set. Statistical comparisons were made using the $t$-test and one- or twoway repeated-measures ANOVA (the Holm-Sidak method was used for multiple comparisons). In all cases, $\mathrm{P}<0.05$ was considered statistically significant.

\section{Results}

\section{Reliability of fVEP responses in normal mice}

The VEP waveform of rodents was first described in rats, defined by $\mathrm{P} 1, \mathrm{~N} 1, \mathrm{P} 2, \mathrm{~N} 2, \mathrm{P} 3$, and N3 peaks (21), and the mouse VEP also showed a similar response by flash stimulation (22) (Figure 2A). All fVEP responses of mice showed that the $\mathrm{N} 1$ wave and $\mathrm{P} 2$ wave were repeatable and stable in all mice, so we focused on the latencies of $\mathrm{N} 1$ and $\mathrm{P} 2$ and the peak-to-peak amplitude of $\mathrm{N} 1-\mathrm{P} 2$. At the beginning of the experiment, 24 mice were eliminated because of unstable anesthesia. The results of fVEP responses from 270 normal mice (540 eyes) showed 


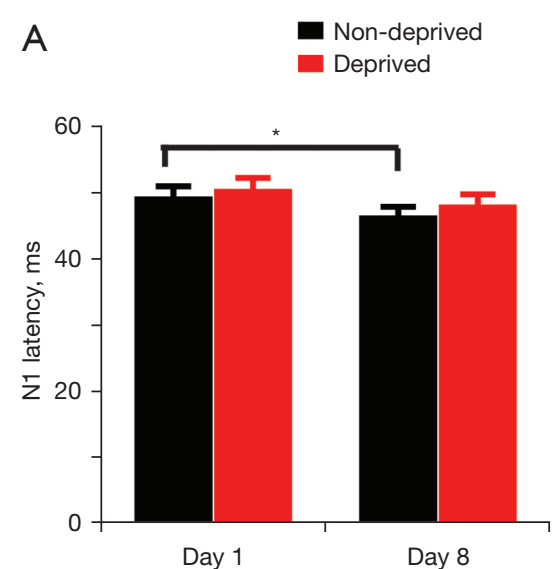

B
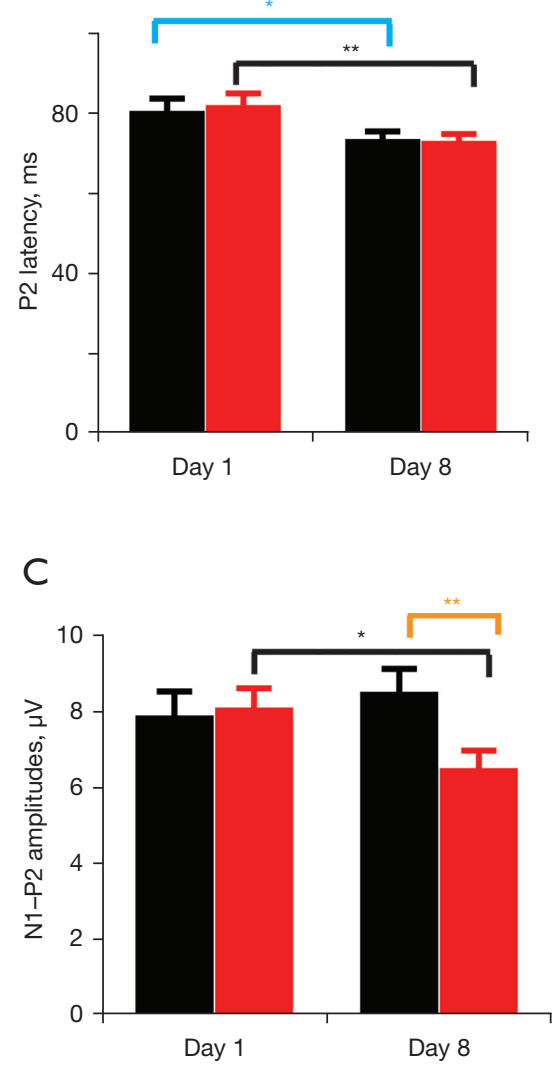

Figure 3 Changes in fVEP after MD for 7 days. (A) The latency of the N1 wave before eyelid suture (day 1) compared to that after suture and reopening of the eye (day 8). (B) The latency of the P2 wave before eyelid suture (day 1 ) compared to that after suture and reopening of the eye (day 8). (C) The amplitudes of the N1-P2 wave before eyelid suture (day 1 ) compared to that after suture and reopening of the eye (day 8). The black bar represents non-deprived eyes and the red bar represents deprived eyes $\left({ }^{*}, \mathrm{P}<0.05\right.$; $\left.{ }^{* *}, \mathrm{P}<0.01\right)$. fVEP, flash visual evoked potentials; $\mathrm{MD}$, monocular deprivation. that the average $\mathrm{N} 1$ and $\mathrm{P} 2$ latencies were $52.44 \pm 0.35$ and $83.39 \pm 0.60 \mathrm{~ms}$, respectively, while the average $\mathrm{N} 1-\mathrm{P} 2$ amplitude was $7.26 \pm 0.14 \mu \mathrm{V}$ (Figure $2 B-2 D$, orange bar). The latencies of $\mathrm{N} 1$ and $\mathrm{P} 2$ and $\mathrm{N} 1-\mathrm{P} 2$ amplitudes recorded from the right eye (Figure $2 B-2 D$, black bar) and left eye (Figure $2 B-2 D$, red bar) did not significantly differ $(\mathrm{P}>0.05)$. These results suggested that the right eye and left eye can each induce stable fVEP responses.

The reliability of the VEP reaction is affected by methodological factors, such as electrode placement and variability of stability $(23,24)$. To verify the reliability of fVEP, we performed continuous recordings for 7 days in 8 mice. The fVEP responses from day 1 to 7 did not show any differences among the latencies of $\mathrm{N} 1$ and $\mathrm{P} 2$, and the amplitude of $\mathrm{N} 1-$ $\mathrm{P} 2$ suggested that $\mathrm{fVEP}$ can be used to compare responses preMD and 7 days after MD (data not shown).

\section{fVEP results of MD mice}

A total of $34 \mathrm{MD}$ mice were recorded. Consistent with the above normal mice, the latencies and amplitudes of N1 and P2 did not show any differences between non-MD and MD mice before the suture surgery (Figure 3, left panels). However, the latencies of $\mathrm{N} 1$ and $\mathrm{P} 2$ responses were significantly shortened in non-deprived eyes after MD (Figure $3 A, 3 B$, black bars; $\mathrm{P}<0.05$ ). Interestingly, the latency of $\mathrm{P} 2$, not $\mathrm{N} 1$, was significantly shorter in $\mathrm{MD}$ eyes after 7 days of deprivation (Figure $3 B ; \mathrm{P}<0.01$ ). The peak-to-peak amplitude of $\mathrm{N} 1$ $\mathrm{P} 2$ in deprived eyes was significantly reduced compared to non-deprived eyes (Figure $3 C ; \mathrm{P}<0.05$ and $\mathrm{P}<0.001$ ). The significantly reduced fVEP responses in $\mathrm{MD}$ eyes suggests impaired retino-cortical connectivity following MD.

\section{LTP results}

To further investigate the MD-induced changes in visual function, we randomly chose $5 \mathrm{MD}$ mice who had confirmed fVEP responses and $5 \mathrm{NC}$ mice for brain slice recordings. First, to determine if basal synaptic transmission in MD mice was altered, the input-output relationship and paired-pulse ratio in MD and NC mouse slices were compared. MD and NC mice did not show any significant differences in the mean fEPSP amplitude evoked by a range of stimulation intensities (Figure $4 A ; \mathrm{P}>0.05$ ). The second fEPSP response over the first fEPSP response in a different stimulation interval also did not significantly differ between $\mathrm{MD}$ and NC mice (Figure $4 B ; \mathrm{P}>0.05$ ). These results suggested that the probability of transmitter release in $\mathrm{MD}$ 

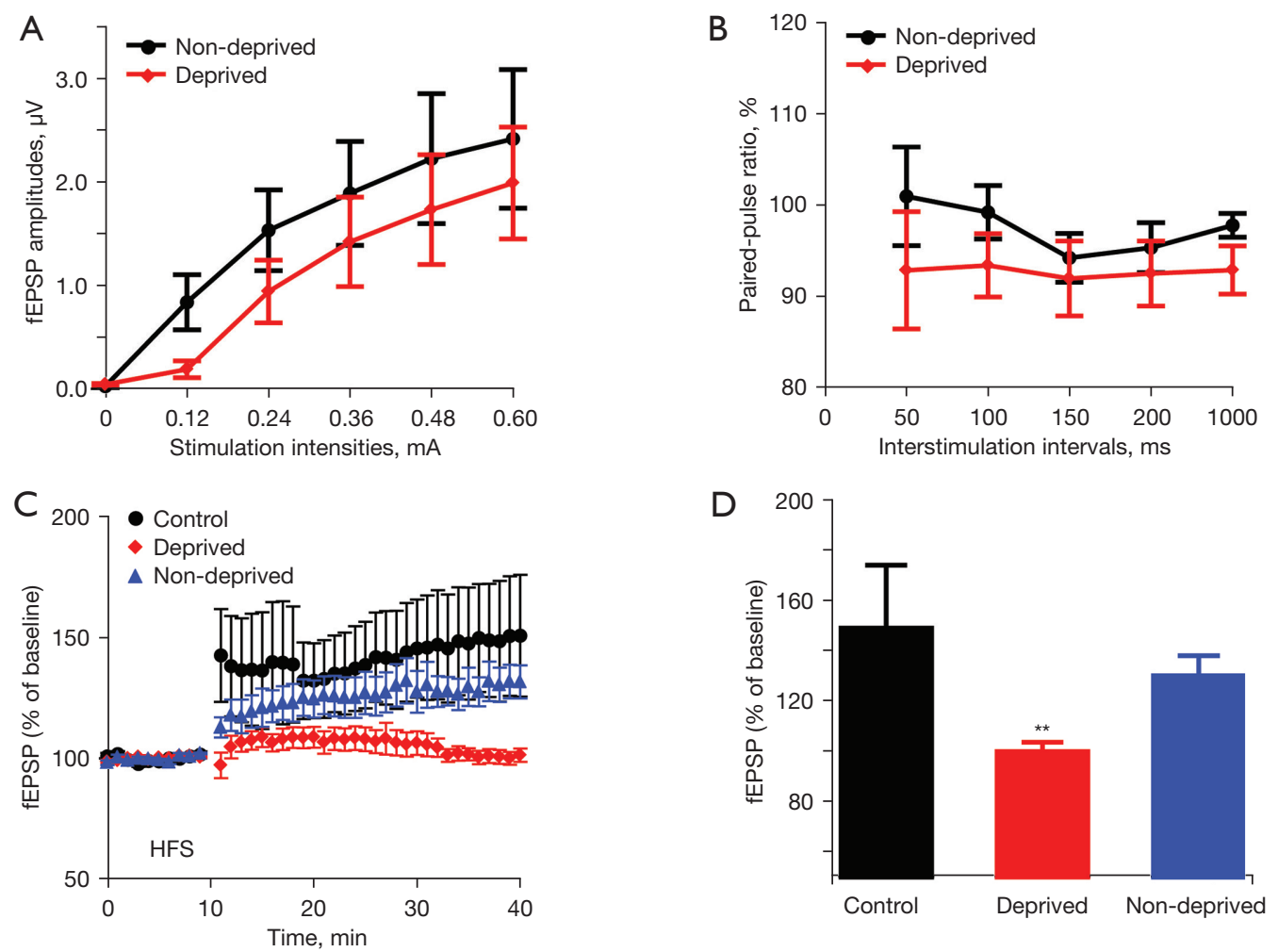

Figure $4 \mathrm{MD}$ impaired LTP in the primary visual cortex slices. (A) The input-output response was generated by stimulating layer IV and recording in layer II/III ( $\mathrm{n}=5$ in each group). (B) Summary of the paired-pulse ratio against different interstimulation intervals. (C) Time course of LTP induced by 2 trains of $100 \mathrm{~Hz}$ stimuli in the visual cortex slices from NC mice ( $\mathrm{n}=7$ slices), the corresponding cortex to the deprived eye ( $\mathrm{n}=11$ slices), and the corresponding cortex to the non-deprived eye ( $\mathrm{n}=9$ slices). (D) Quantitative analysis of fEPSP potentiation was determined at a mean of 40 minutes after HFS (** $\mathrm{P}<0.01)$. MD, monocular deprivation; LTP, long-term potentiation; NC, normal control; fEPSP, field excitatory postsynaptic potential; HFS, high-frequency stimulation.

and NC mice was similar.

To induce LTP in the primary visual cortex, HFS was applied to layers II/III, which produced a significant increase in fEPSP lasting at least 2 hours $(149.75 \% \pm 24.15 \%$; $\mathrm{n}=7$; Figure $4 C, 4 D$, black). However, the same HFS applied to the visual cortex in MD mice failed to induce LTP $(100.68 \% \pm 2.76 \% ; \mathrm{n}=11 ; \mathrm{P}>0.05 ;$ Figure $4 C, 4 D$, red). In contrast to the MD dominant cortex, the same HFS from the non-deprived dominant cortex could induce LTP significantly in $\mathrm{MD}$ mice $(130.74 \% \pm 7.02 \% ; \mathrm{n}=9 ; \mathrm{P}>0.05$; Figure $4 C, 4 D$, blue), and did not differ from the NC mice $(\mathrm{P}>0.05)$. These results were consistent with the fVEP finding that MD significantly impairs visual plasticity.

\section{Behavioral experiment results}

Both fVEP and LTP are physiological indicators used to evaluate mouse visual function, so we conducted behavioral experiments to evaluate mouse visual function from a psychophysics perspective. Firstly, to determine mouse vision in the visual water box, $15 \mathrm{NC}$ mice were trained daily for 7 days without any visible signs. From day 8 to 10 , the visible signs were placed on the sides of the walls of both channels. On day 11, the visible signs were removed to compare to the previous day with signs. The time to reach the escape platform each day is shown in Figure $5 A$. The time to the platform on the last day (day 7) was slightly shorter than that of the first day, but this was not significant $(15.37 \pm 1.77$ vs. $20.11 \pm 2.75 ; \mathrm{P}>0.05)$. However, once we placed the visible signs on the walls, the time to reach the platform was much shorter than that in the trials with removed signs $(12.18 \pm 1.21$ vs. $17.36 \pm 1.24$; Figure $5 B$; $\mathrm{P}<0.01)$. We also plotted success rates or accuracy rates of reaching rescue platform for each day. The accuracy 

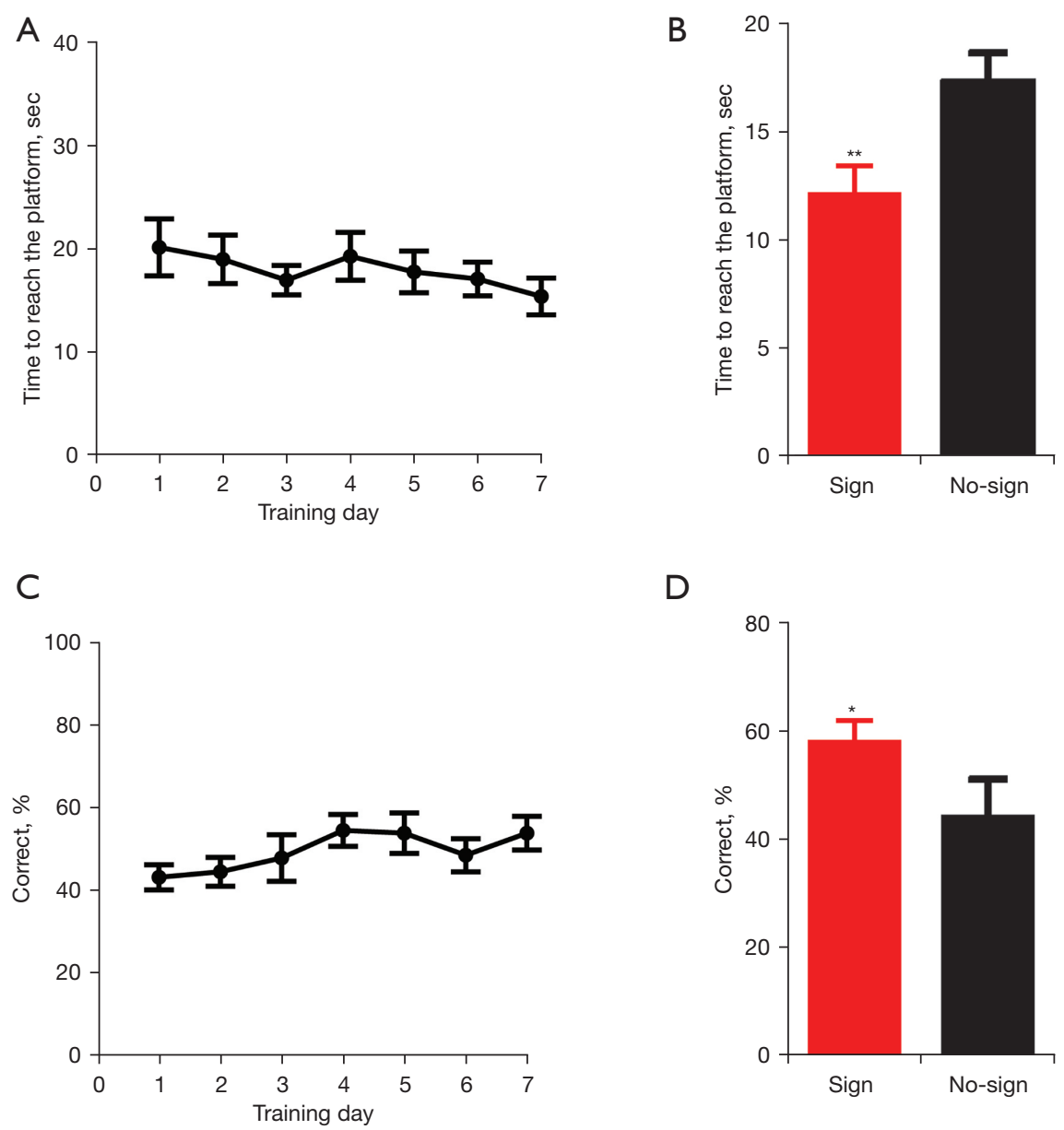

Figure 5 In the visual water tasks, the average times and success rates for 15 mice to reach the escape platform were tested over 7 days. (A) The time to reach the platform on each of the 7 days of testing in the visual behavioral task. (B) The time to reach the platform on day 10 with visible signs (red) and day 11 without visible signs in the visual behavioral task. (C) The success rates (direct from the release chute to the platform) on each of the 7 days of testing in the visual behavioral task. (D) The success rates on day 10 with visible signs (red) and on day 11 without visible signs in the visual behavioral task $\left({ }^{*}, \mathrm{P}<0.05 ;{ }^{* *}, \mathrm{P}<0.01\right)$.

rate means the percentage of times of directly reaching platform to times of total tests. The accuracy rates on the last day were higher than those on the first day of training $(52.1 \% \pm 4.8 \%$ vs. $43.3 \% \pm 3.0 \%$; Figure 5 C; $\mathrm{P}<0.05)$. Similarly, the accuracy rates were higher when the visible signs were present on day 10 than those without visible signs on the walls at day $11(58.5 \% \pm 3.6 \%$ vs. $44.6 \% \pm 6.6 \%$; Figure $5 D ; \mathrm{P}<0.05)$. These results suggested that the time to reach the escape platform and the success rates are dependent on the mouse's vision.

To further evaluate the performance of MD mice in behavioral tasks, 17 mice in the MD group were reversely sutured, and 17 mice of the NC group that randomly had 1 eye sutured underwent behavioral testing. Figure 6 shows the representative swim paths on day 1 (left) and day 7 (right) from an NC (Figure 6A) and MD (Figure 6B) mouse. Figure $6 C$ shows that mice in the $\mathrm{MD}$ group spent more time reaching the rescue platform than those in the $\mathrm{NC}$ group each day $(\mathrm{P}<0.01)$. On day 7 , the average time to reach the platform was $20.30 \pm 1.87$ seconds for $M D$ mice and $15.40 \pm 1.58$ seconds for NC mice (Figure $6 C ; \mathrm{P}<0.05$ ). When the grating was placed on the front of the platform, the time to reach the platform was significantly longer in the MD group than in the NC group $(16.94 \pm 2.26 v s$. $13.92 \pm 1.66$; Figure $6 D ; \mathrm{P}<0.01)$. When the grating was taken off the front of the platform, the time to reach the platform was similar in both groups $(20.03 \pm 3.58 \mathrm{vs}$. $20.49 \pm 2.25$; Figure $6 D ; \mathrm{P}>0.05)$. The accuracy rates on 
A NC day 1
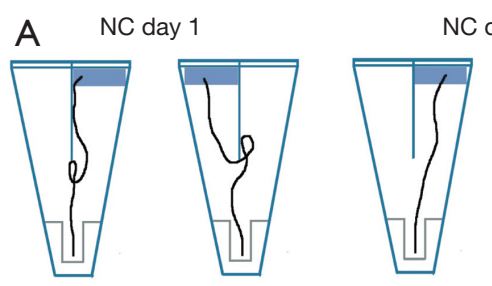

NC day 7

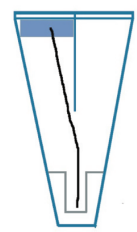

C

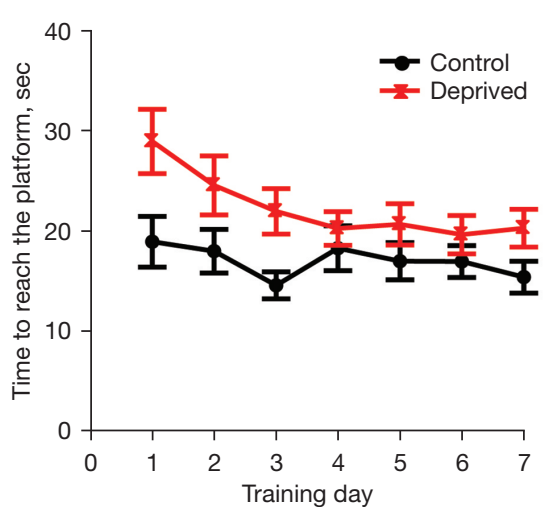

B
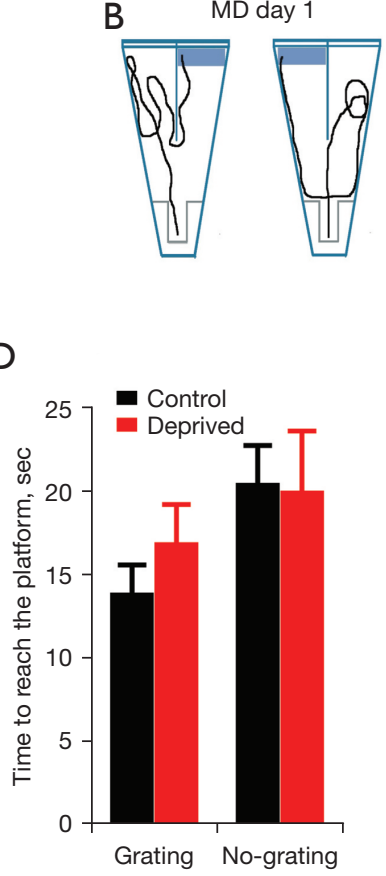

E

MD day 7
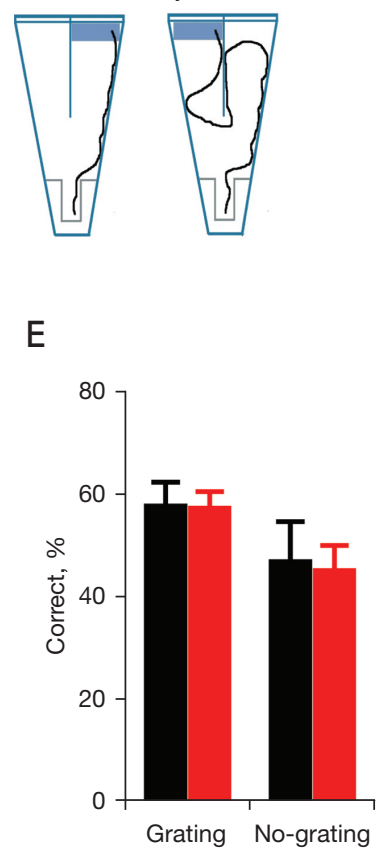

Figure $6 \mathrm{MD}$ prolongs the time to arrive at the platform. (A) Representative swim paths on day 1 (left) and day 7 (right) from a NC mouse. (B) Representative swim paths on day 1 (left) and day 7 (right) from an MD mouse. (C) The time to reach the platform for NC mice (black, $\mathrm{n}=17$ ) and MD mice ( $\mathrm{n}=17$, red) on each of the 7 days of testing in the visual behavioral task. (D) The time to reach the platform on day 10 with grating (left panel) and day 11 without grating (right panel) in both groups in the visual behavioral task. (E) The success rates on day 10 with grating (left panel) and on day 11 without grating (right panel) in the visual behavioral task. MD, monocular deprivation; NC, normal control.

Table 1 Correlation coefficients of measurements between control and MD mice

\begin{tabular}{lcc}
\hline Measurements & Parameters & Correlation coefficient \\
\hline fVEP & N1 latency & 0.064913 \\
& P2 latency & 0.285855 \\
& N1-P2 amplitudes & 0.275184 \\
LTP & LTP magnitudes (\%) & 0.574178 \\
Behavioral testing & Time to platform & -0.34395 \\
& Accuracy rate & -0.06092 \\
\hline
\end{tabular}

MD, monocular deprivation; fVEP, flash visual evoked potentials; LTP, long-term potentiation.

day 10 with gratings in front of the platform and day 11 without gratings showed a significant difference in both groups (Figure $6 E ; \mathrm{P}<0.05$ ), while there was no significant difference in the accuracy rates between the MD group and the NC group either with a grating or without grating in front of the platform. These results suggest that this visual water box can distinguish mouse vision, and successfully reaching the platform is dependent on mouse vision.

\section{Comparisons of fVEP, LTP, and behavioral tests}

To determine the correlation between fVEP, LTP, behavioural tests for assessing vision in mice, we analyzed the correlation coefficients between the control group (eyes) and the MD group (eyes) in terms of fVEP, LTP, or behavioral testing. The correlation coefficients are presented in Table 1. LTP had better sensitivity to MD, while the sensitivity of fVEP was lower than that of behavioral testing.

\section{Discussion}

The visual system is responsible for accomplishing many tasks with various complexities, ranging from adjusting the pupillary diameter and tracking moving targets to discerning spatial details and colors in the objects being viewed. With 
the rapid development of genetic technology and biological research in various fields, mice have become the most widely studied mammalian model. As a result, mouse vision detection becomes more important in the visual system. There are many ways to measure mouse vision. These methods all have advantages and limitations. For example, ERG mainly provides information about whether mouse retinal cells have an appropriate response to light stimulation. The optokinetic reflex (OKR) or OMR is an excellent method for assessing contrast sensitivity and spatial resolution. However, the OKR requires the fixator's surgical attachment to the mouse skull $(25,26)$. The OMR requires training the experimenter to subjectively detect tiny mouse head movements in response to the moving grating in the light drum $(26,27)$. Therefore, no single test method can be used as a comprehensive test of visual function.

VEP is an objective, effective, and non-invasive method to study visual function, and is mainly divided into pattern visual evoked potential (pVEP) and fVEP. The fVEP is an electrical activity transmitted to the visual cortex of the occipital lobe through the visual pathway by flashing the retina, reflecting the functional state of the retinal ganglion cells to the visual cortex. The fVEP detection does not dependent on the subjective response to inspection, and it can also more accurately reflect the state of the function of the visual system for the people with inattention. The requirements for recording $\mathrm{pVEP}$ in mice are high, while recording fVEP is simple and its waveform is easy to identify. Due to the different methods of recording and stimulation in different laboratories, the latencies and amplitudes of fVEP responses under different conditions (electrodes type, different stimulation intensities and rates, different anesthetic agents) may yield various parameters (5-7,19,21,22). We tested fVEP under the same experimental conditions and by the same operator to obtain stable and repeatable waveforms. By testing the fVEP of 270 normal mice as well as by consecutive testing of 8 normal mice for 7 days, we found that the peak-to-peak amplitude of N1-P2 was the most stable indicator. The finding of significantly reduced $\mathrm{N} 1-\mathrm{P} 2$ amplitude in deprived mice was consistent with previous reports in mice $(28,29)$ and rats $(30,31)$. Nobel laureates Hubel and Wiesel's research on the neuroplasticity of the visual cortex induced by MD was the beginning of many branches of visual plasticity research (16-18). The subsequent discovery of LTP in the hippocampus has been extensively studied in learning and memory neurophysiology. LTP indicates enhanced synaptic plasticity in the visual cortex, while LTP impairment indicates decreased or lost synaptic plasticity in the visual cortex. The present study showed that the LTP of the visual cortex V1 area of deprived eyes was impaired, while the input-output curve and paired-pulse ratio did not change, suggesting that short-term deprivation mainly interrupts synaptic plasticity, not basal synaptic transmission or presynaptic release. These results were also in line with a previous report (32). VEP is a local field potential consisting of a small number of synapses around the recording electrode (33). LTP impairment suggests that V1 area synaptic activity decreased after MD, reducing the VEP response recorded from the scalp above the V1 area.

Visual behavior experiments are another critical method of visual function testing in mice. A classic method to test the visual function of mice is to measure the optokinetic response of the eyes or head to a large moving stimulus $(25-27,34)$. It has been reported that the acuity for stationary targets depends mainly on geniculo-cortical processing, while the moving targets are processed in the subcortical provision system (35). Therefore, researchers are likely to test the stationary targets in the behavioral task that imitate the most widely used Morris water maze for learning and memory assessment $(13,14,36-38)$. Behavioral experiments are a non-invasive and psychophysical way to measure visual capabilities, and therefore, they are a compliment to electrophysiological methods of assessing visual thresholds. A change in spatial frequency on the gratings could detect the visual acuity of mice. Our study, which only used 1 grating, still showed the visual deficits of MD mice, which is consistent with the literature $(37,38)$. Therefore, our study demonstrated that fVEP and synaptic plasticity physiological changes were in line with the psychophysical measurement. A physiological and straightforward method for assessing vision in mice is fVEP. The change in N1P2 amplitude from repeated tests can be used as a reliable evaluation indicator. Behavioral tests by force swimming tasks also reflect the activity of the primary visual cortex. Future studies which combine pVEP and the visual water test using different spatial frequencies and contrast gratings, then analyze synaptic plasticity or synaptic scaling of the primary visual cortex in the same mouse, will help us understand visual function in greater detail as well as related diseases such as amblyopia. Amblyopia is an eye disease that occurs during the visual development period. If amblyopia is actively treated during the sensitive period of visual development, the possibility of visual function recovery is very high because the visual cortex is highly plastic at this time, during this period, the visual system adjusts and changes the neural 
connection and synaptic structure with born according to the stimulation of the visual environment, so the amblyopia treatment effect is good. However, the visual development period does not end suddenly but gradually stops. Study (39) has shown that the visual brain of adults maintains a kind of developmental plasticity, which brings hope for adult patients with amblyopia. However, it is important to acknowledge that this neuroplasticity is a very slow process, and the quality of the regained visual perception is limited.

\section{Conclusions}

The present study demonstrated that fVEP and synaptic plasticity changes were consistent with the psychophysical measurement results. Synaptic plasticity is the best indicator for visual dysfunction induced by MD. A physiological and straightforward method for assessing mouse vision is fVEP. The change in N1-P2 amplitude from repeated tests can be used as a reliable evaluation indicator. Behavioral tests by forced swimming tasks also reflect the activity of the primary visual cortex.

\section{Acknowledgments}

Funding: This study was funded by the Regional Science Foundation of National Natural Science Foundation of China (81860180) and the Science and Technology Project of Yunnan Province (2016IA022).

\section{Footnote}

Reporting Checklist: The authors have completed the ARRIVE reporting checklist. Available at https://atm. amegroups.com/article/view/10.21037/atm-21-6723/rc

Data Sharing Statement: Available at https://atm.amegroups. com/article/view/10.21037/atm-21-6723/dss

Conflicts of Interest: All authors have completed the ICMJE uniform disclosure form (available at https://atm. amegroups.com/article/view/10.21037/atm-21-6723/coif). The authors have no conflicts of interest to declare.

Ethical Statement: The authors are accountable for all aspects of the work in ensuring that questions related to the accuracy or integrity of any part of the work are appropriately investigated and resolved. All animal experiments were approved by the Kunming Medical
University Animal Care Committee (No. kmmu2018010), and all procedures were conducted in accordance with the Association for Research in Vision and Ophthalmology (ARVO) Statement for Use of Animals in Ophthalmic Vision and Research.

Open Access Statement: This is an Open Access article distributed in accordance with the Creative Commons Attribution-NonCommercial-NoDerivs 4.0 International License (CC BY-NC-ND 4.0), which permits the noncommercial replication and distribution of the article with the strict proviso that no changes or edits are made and the original work is properly cited (including links to both the formal publication through the relevant DOI and the license). See: https://creativecommons.org/licenses/by-nc-nd/4.0/.

\section{References}

1. Saari JC. Biochemistry of visual pigment regeneration: the Friedenwald lecture. Invest Ophthalmol Vis Sci 2000;41:337-48.

2. Burns ME, Pugh EN Jr. Lessons from photoreceptors: turning off g-protein signaling in living cells. Physiology (Bethesda) 2010;25:72-84.

3. Seabrook TA, Burbridge TJ, Crair MC, et al. Architecture, Function, and Assembly of the Mouse Visual System. Annu Rev Neurosci 2017;40:499-538.

4. Pinto LH, Enroth-Cugell C. Tests of the mouse visual system. Mamm Genome 2000;11:531-6.

5. Peachey NS, Ball SL. Electrophysiological analysis of visual function in mutant mice. Doc Ophthalmol 2003;107:13-36.

6. Ridder WH 3rd, Nusinowitz S. The visual evoked potential in the mouse--origins and response characteristics. Vision Res 2006;46:902-13.

7. Tomiyama Y, Fujita K, Nishiguchi KM, et al. Measurement of Electroretinograms and Visually Evoked Potentials in Awake Moving Mice. PLoS One 2016;11:e0156927.

8. Huberman AD, Niell CM. What can mice tell us about how vision works? Trends Neurosci 2011;34:464-73.

9. Siemann JK, Muller CL, Bamberger G, et al. A novel behavioral paradigm to assess multisensory processing in mice. Front Behav Neurosci 2015;8:456.

10. Thompson S, Philp AR, Stone EM. Visual function testing: a quantifiable visually guided behavior in mice. Vision Res 2008;48:346-52.

11. Histed MH, Carvalho LA, Maunsell JH. Psychophysical measurement of contrast sensitivity in the behaving mouse. J Neurophysiol 2012;107:758-65. 
12. Koehler CC, Hall LM, Hellmer CB, et al. Using Looming Visual Stimuli to Evaluate Mouse Vision. J Vis Exp 2019. doi: $10.3791 / 59766$.

13. Prusky GT, West PW, Douglas RM. Behavioral assessment of visual acuity in mice and rats. Vision Res 2000;40:2201-9.

14. Leinonen H, Tanila H. Vision in laboratory rodents-Tools to measure it and implications for behavioral research. Behav Brain Res 2018;352:172-82.

15. Vorhees CV, Williams MT. Assessing spatial learning and memory in rodents. ILAR J 2014;55:310-32.

16. Hubel DH, Wiesel TN. Effects of monocular deprivation in kittens. Naunyn Schmiedebergs Arch Exp Pathol Pharmakol 1964;248:492-7.

17. Wiesel TN, Hubel DH. Single-cell responses in striate cortex of kittens deprived of vision in one eye. J Neurophysiol 1963;26:1003-17.

18. Barrett BT, Bradley A, McGraw PV. Understanding the neural basis of amblyopia. Neuroscientist 2004;10:106-17.

19. Strain GM, Tedford BL. Flash and pattern reversal visual evoked potentials in C57BL/6J and B6CBAF1/J mice. Brain Res Bull 1993;32:57-63.

20. Kirkwood A, Silva A, Bear MF. Age-dependent decrease of synaptic plasticity in the neocortex of alphaCaMKII mutant mice. Proc Natl Acad Sci U S A 1997;94:3380-3.

21. Creel DJ, Dustman RE, Beck EC. Visually evoked responses in the rat, guinea pig, cat, monkey, and man. Exp Neurol 1973;40:351-66.

22. Tebano MT, Luzi M, Palazzesi S, et al. Effects of cholinergic drugs on neocortical EEG and flash-visual evoked potentials in the mouse. Neuropsychobiology 1999;40:47-56.

23. Porciatti V, Pizzorusso T, Maffei L. Vision in mice with neuronal redundancy due to inhibition of developmental cell death. Vis Neurosci 1999;16:721-6.

24. Klistorner AI, Graham SL, Grigg JR, et al. Electrode position and the multi-focal visual-evoked potential: role in objective visual field assessment. Aust N Z J Ophthalmol 1998;26 Suppl 1:S91-4.

25. Cahill H, Nathans J. The optokinetic reflex as a tool for quantitative analyses of nervous system function in mice: application to genetic and drug-induced variation. PLoS One 2008;3:e2055.

26. Kretschmer F, Sajgo S, Kretschmer V, et al. A system to measure the Optokinetic and Optomotor response in mice. J Neurosci Methods 2015;256:91-105.

27. Lu Q, Ganjawala TH, Hattar S, et al. A Robust Optomotor Assay for Assessing the Efficacy of Optogenetic Tools for Vision Restoration. Invest Ophthalmol Vis Sci
2018;59:1288-94.

28. Lickey ME, Pham TA, Gordon B. Swept contrast visual evoked potentials and their plasticity following monocular deprivation in mice. Vision Res 2004;44:3381-7.

29. Kang E, Durand S, LeBlanc JJ, et al. Visual acuity development and plasticity in the absence of sensory experience. J Neurosci 2013;33:17789-96.

30. Guire ES, Lickey ME, Gordon B. Critical period for the monocular deprivation effect in rats: assessment with sweep visually evoked potentials. J Neurophysiol 1999;81:121-8.

31. Sale A, Maya Vetencourt JF, Medini P, et al. Environmental enrichment in adulthood promotes amblyopia recovery through a reduction of intracortical inhibition. Nat Neurosci 2007;10:679-81.

32. Nataraj K, Turrigiano G. Regional and temporal specificity of intrinsic plasticity mechanisms in rodent primary visual cortex. J Neurosci 2011;31:17932-40.

33. Katzner S, Nauhaus I, Benucci A, et al. Local origin of field potentials in visual cortex. Neuron 2009;61:35-41.

34. Tabata H, Shimizu N, Wada Y, et al. Initiation of the optokinetic response (OKR) in mice. J Vis 2010;10:13.1-17.

35. Douglas RM, Alam NM, Silver BD, et al. Independent visual threshold measurements in the two eyes of freely moving rats and mice using a virtual-reality optokinetic system. Vis Neurosci 2005;22:677-84.

36. Wong AA, Brown RE. Visual detection, pattern discrimination and visual acuity in 14 strains of mice. Genes Brain Behav 2006;5:389-403.

37. Wang Y, Wu W, Zhang X, et al. A Mouse Model of Visual Perceptual Learning Reveals Alterations in Neuronal Coding and Dendritic Spine Density in the Visual Cortex. Front Behav Neurosci 2016;10:42.

38. Hosang L, Yusifov R, Löwel S. Long-Term Visual Training Increases Visual Acuity and Long-Term Monocular Deprivation Promotes Ocular Dominance Plasticity in Adult Standard Cage-Raised Mice. eNeuro 2018. doi: 10.1523/ENEURO.0289-17.2017.

39. Castaldi E, Lunghi C, Morrone MC. Neuroplasticity in adult human visual cortex. Neurosci Biobehav Rev 2020;112:542-52.

(English Language Editor: C. Betlazar-Maseh)

Cite this article as: Ding S, Yang C, Zhu H, Li S, Li L. Assessing the impact of monocular deprivation on visual evoked potentials, behavior, and visual plasticity in juvenile mice. Ann Transl Med 2022;10(3):141. doi: 10.21037/atm-21-6723 